\title{
Intercomparison of Results for a PWR Rod Ejection Accident
}

\author{
D.J. Diamond, A. Aronson, and J. Jo \\ Brookhaven National Laboratory ${ }^{1}$ \\ Upton, NY, USA \\ A. Avvakumov, V. Malofeev, and V. Sidorov \\ Russian Research Centre - Kurchatov Institute \\ Moscow, Russia \\ P. Ferraresi and C. Gouin \\ Institute for Protection and Nuclear Safety \\ Cadarache, France \\ S. Aniel and M.E. Royer \\ Atomic Energy Commission (CEA) \\ Saclay, France
}

\begin{abstract}
This study is part of an overall program to understand the uncertainty in best-estimate calculations of the local fuel enthalpy during the rod ejection accident. Local fuel enthalpy is used as the acceptance criterion for this design-basis event and can also be used to estimate fuel damage for the purpose of determining radiological consequences. The study used results from neutron kinetics rnodels in PARCS, BARS, and CRONOS2, codes developed in the United States, the Russian Federation, and France, respectively. Since BARS uses a heterogeneous representation of the fuel assembly as opposed to the homogeneous representations in PARCS and CRONOS, the effect of the intercomparison was primarily to compare different intra-assembly models. Quantitative comparisons for core power, reactivity, assembly fuel enthalpy and pin power were carried out. In general the agreement between methods was very good providing additional confidence in the codes and providing a starting point for a quantitative assessment of the uncertainty in calculated fuel enthalpy using best-estimate methods.
\end{abstract}

This work was performed under the auspices of the U. S. Nuclear Regulatory Commission under Contract No. DE-AC02-98CH10886.

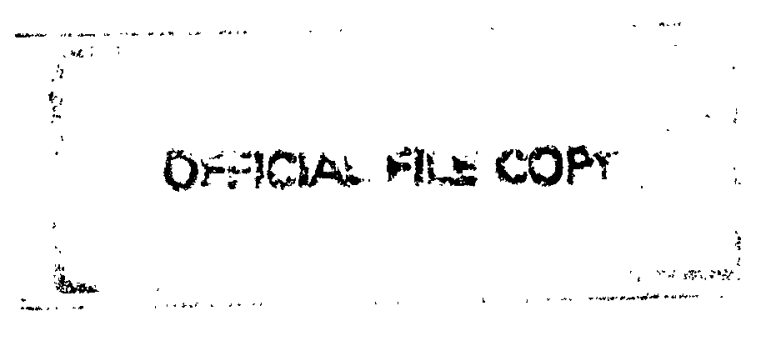




\section{$\underline{\text { Introduction }}$}

The rod ejection accident (REA) is the design-basis reactivity initiated event for a pressurized water reactor (PWR). The acceptance criterion for unacceptable fuel damage during the event is in terms of peak local fuel enthalpy. The criterion for determining if any fuel damage has occurred, for the sake of assessing the radiological consequences, has traditionally been reaching the limiting departure-from-nucleate-boiling ratio but recent research has led to the conclusion that the criterion for moderate to high burnup fuel should also be a limiting value for local fuel enthalpy [1]. When the calculation of fuel enthalpy is done with best-estimate methods it is important to also understand the uncertainty in the results. To improve our understanding of that uncertainty, an intercomparison of the results for an REA using different methods from the U.S., France, and the Russian Federation (R.F.) has been carried out. Since some of the methods treat the fuel assembly as a homogenous region, and some use an explicit representation of each fuel pin or fuel cell, the difference in results was, to a large extent, a reflection of the uncertainty introduced by the simpler representation. Hence, this intercomparison partially satisfies the overall objective of determining the uncertainty in these calculations. In this paper the methods used are discussed first and then the REA problem used for the intercomparison is specified. Results of the intercomparison are then given and conclusions, based on those results, are explained.

\section{Calculational Methodology}

The calculations carried out in the U.S. were done with the PARCS/RELAP5 code system [2] used by the U.S. Nuclear Regulatory Commission and others, those done in the R.F. were done with BARS/RELAP5 [3] which was developed at the Russian Research Centre, Kurchatov Institute, and those done in France used a code system (SAPHYR) used by the Institute for Nuclear Safety and Protection, composed of three codes, APOLLO2 [4], CRONOS2 [5], and FLICA4 [6]. The neutron kinetics part of these code systems is PARCS, BARS, and CRONOS2, respectively.

PARCS uses a nodal approximation wherein each fuel assembly is homogenized and the two-group flux is calculated in each axial mesh of either the full assembly or a subregion of the assembly. The assembly is homogenized in the sense that the cross sections are uniform across the assembly and the thermal-hydraulic parameters are calculated for an average channel representing the assembly. The power in individual fuel rods at each time of interest can be obtained from a flux reconstruction option. This latter model requires as input the pin-by-pin flux distribution for an isolated assembly at nominal conditions.

BARS uses a Green's function approach wherein each fuel pin is represented explicitly in the radial plane. The Green's functions are based on diffusion theory and the calculation is typically done using four or five energy groups. In the axial direction an harmonic expansion is used to represent the flux. Although each pin is represented explicitly in the neutronics calculation, the fuel temperature for each pin is based on an assemblyaverage calculation.

CRONOS2 uses two neutron energy groups and three-dimensional diffusion theory and can either represent an homogenized assembly [CRONOS2(HOM)] or represent every fuel cell explicitly in the assembly [CRONOS2(HET)]. In the latter case, cross sections are needed for homogenized fuel cells, and for cells containing a guide tube and/or a burnable poison rod or control rod, depending on assembly design. As with all the other codes, the thermal-hydraulics is obtained for the assembly average (although it does have the ability to do four thermal-hydraulic channels in an average assembly or a subchannel calculation in selected regions). 
The major difference between the codes was the intra-assembly representation and the intercomparison was expected to highlight the effect of that modeling for the dynamics of the REA. However, there are other differences between the codes and it is difficult to assess their impact. For example, the codes use different data sources. PARCS and CRONOS2(HOM) use the same two-group cross sections generated with the CASMO- 3 code. BARS uses four-group lambda matrices generated with the TRIFON code. Both CASMO- 3 and TRIFON use the same ENDF/B libraries.

The reactor model was based on Three Mile Island Unit 1 and made use of data available for an international benchmark exercise [7]. The reactor has one-eighth core symmetry and at hot zero power (HZP) has control banks inserted as shown on Figure 1. Figure 1 also shows the burnup for each assembly which extends up to $58 \mathrm{GWd} / \mathrm{t}$, close to the licensing limit for PWRs in the U.S.

FIGURE 1. ONE-EIGHTH CORE REPRESENTATION WITH ASSEMBLY BURNUP, GWD/T

\begin{tabular}{|c|c|c|c|c|c|c|c|}
\hline $\begin{array}{l}53 \text { A } \\
\text { Bank } 7\end{array}$ & $\begin{array}{l}30 \\
(9 \mathrm{H})\end{array}$ & 56 & 31 & $\begin{array}{l}50 \quad \text { B } \\
\text { Bank } 7\end{array}$ & 28 & $\begin{array}{l}54 \\
\text { Bank } 6\end{array}$ & 56 \\
\hline & 58 & 31 & 55 & 30 & $\begin{array}{l}54 \\
\text { Bank } 5\end{array}$ & 26 & 49 \\
\hline & & $\begin{array}{l}58 \\
\text { Bank } 6\end{array}$ & 30 & 54 & 28 & 23 & 47 \\
\hline & & & $\begin{array}{l}50 \\
\text { Bank } 5\end{array}$ & 29 & 53 & 41 & \\
\hline \multicolumn{2}{|c|}{ Regulating Bank } & & & $\begin{array}{l}49 \quad \mathrm{C} \\
\text { Bank } 7\end{array}$ & 24 & 41 & \\
\hline & & & & & 37 & & \\
\hline
\end{tabular}

An attempt was made to make each reactor model as equivalent as possible. All models used an axial mesh of 24 nodes within the core and the codes run with an homogenized assembly representation [PARCS and CRONOS2(HOM)] used a $2 \times 2$ mesh radially within the assembly. PARCS and BARS used the same thermalhydraulics model (RELAP5) and all methods used similar thermal-hydraulic options to the extent possible, e.g., the same gap conductance and the same correlation for Doppler temperature in terms of pellet centerline and surface temperature. The most difficult representation for BARS to make equivalent was the core-reflector interface. 
In order to assure that the models were equivalent a set of steady state calculations were defined as given in Table 1. Suggested acceptance criteria for the difference between calculations were agreed to by the participants. These are also given in the table. The results for the reactivity parameters are given in Table 2 (refer to Figure 1 for location of control rods). Also given in Table 2 are the differences relative to PARCS which was taken as the base case for convenience. The results using SAPHYR, in this table and throughout this paper, are based on using CRONOS2(HOM) and since these calculations used the same two-group data set as used by PARCS, it is not surprising that the results are almost identical. Although BARS uses different data and different neutron balance equations, the results are in good agreement with those from PARCS and CRONOS2 indicating the desired equivalence of the models in all three codes. This equivalence is further demonstrated by the comparisons of average radial and axial power distributions shown in Figures 2 and 3, respectively.

\begin{tabular}{|c|c|}
\hline TABLE 1. COMPARISON OF STEADY STATE PARAMETERS \\
\hline PARAMETER & SUGGESTED CRITERIA \\
\hline $\mathrm{k}_{\text {eff }}$ at HZP (Banks 5-7 in) & $\mathrm{k}_{\text {eff }}$ should be within $\pm 1000 \mathrm{pcm}$ \\
\hline Worth of Bank 5, 6,7 & $\begin{array}{c}\text { Relative difference of each bank worth } \\
\text { within } \pm 15 \%\end{array}$ \\
\hline Worth of each rod in Bank 7 & $\begin{array}{c}\text { Absolute difference of worths within (not } \\
\text { specified) }\end{array}$ \\
\hline Doppler defect (all rods out) & Relative difference within $\pm 25 \%$ \\
\hline $\begin{array}{c}\text { Isothermal temperature coefficient } \\
\text { (HZP with 5 K change) }\end{array}$ & $\begin{array}{c}\text { Difference in ITC within } \pm 4 \text { pcm } / \mathrm{K} \\
\text { Radial core power distribution at HZP }\end{array}$ \\
\hline
\end{tabular}




\section{TABLE 2. STEADY STATE PARAMETERS}

\begin{tabular}{|l|c|c|c|}
\hline & PARCS/R5 & BARS/R5 (B-P) & SAPHYR (S-P) \\
\hline k-eff & 1.00187 & $1.00226(39 \mathrm{pcm})$ & $1.00165(-22 \mathrm{pcm})$ \\
\hline$\rho_{5}$ & $1423 \mathrm{pcm}$ & $1524 \mathrm{pcm}(7.1 \%)$ & $1427 \mathrm{pcm}(0.3 \%)$ \\
\hline$\rho_{6}$ & $849 \mathrm{pcm}$ & $868 \mathrm{pcm}(2.2 \%)$ & $847 \mathrm{pcm}(-0.2 \%)$ \\
\hline$\rho_{7}$ & $1050 \mathrm{pcm}$ & $1085 \mathrm{pcm}(3.3 \%)$ & $1048 \mathrm{pcm}(-0.2 \%)$ \\
\hline$\rho_{7 \mathrm{~A}}$ & $347 \mathrm{pcm}$ & $372 \mathrm{pcm}(25 \mathrm{pcm})$ & $345 \mathrm{pcm}(-2 \mathrm{pcm})$ \\
\hline$\rho_{7 \mathrm{~B}}$ & $188 \mathrm{pcm}$ & $208 \mathrm{pcm}(20 \mathrm{pcm})$ & $188 \mathrm{pcm}(0)$ \\
\hline$\rho_{7 \mathrm{C}}$ & $344 \mathrm{pcm}$ & $473 \mathrm{pcm}(129 \mathrm{pcm})$ & $353 \mathrm{pcm}(9 \mathrm{pcm})$ \\
\hline$\Delta \mathrm{D}$ & $2382 \mathrm{pcm}$ & $2235 \mathrm{pcm}(-6.2 \%)$ & $2365 \mathrm{pcm}(-0.7 \%)$ \\
\hline ITC & $-47.9 \mathrm{pcm} / \mathrm{K}$ & $-46.8 \mathrm{pcm} / \mathrm{K}(1.1 \mathrm{pcm} / \mathrm{K})$ & $-47.5 \mathrm{pcm} / \mathrm{K}(0.4 \mathrm{pcm} / \mathrm{K})$ \\
\hline
\end{tabular}

FIGURE 2. AVERAGE RADIAL POWER DISTRIBUTION, TIME=0

\begin{tabular}{|c|c|c|c|c|c|c|c|}
\hline $\begin{array}{l}0.92 \\
0.87\end{array}$ & $\begin{array}{l}1.88 \\
1.79\end{array}$ & $\begin{array}{l}1.58 \\
1.52\end{array}$ & $\begin{array}{l}1.60 \\
1.56\end{array}$ & $\begin{array}{l}0.67 \\
0.65\end{array}$ & $\begin{array}{l}0.85 \\
0.82\end{array}$ & $\begin{array}{l}0.39 \\
0.38\end{array}$ & $\begin{array}{l}0.28 \\
0.27\end{array}$ \\
\hline & 1.52 & 1.72 & 1.28 & 1.25 & 0.61 & 0.93 & 0.39 \\
\hline & 1.45 & 1.66 & 1.25 & 1.25 & 0.62 & 0.96 & 0.39 \\
\hline & & 0.82 & 1.32 & 1.10 & 1.31 & 1.11 & 0.40 \\
\hline & & 0.79 & 1.31 & 1.17 & 1.37 & 1.16 & 0.41 \\
\hline & & & 0.68 & 1.24 & 1.05 & 0.79 & \\
\hline & & & 0.67 & 1.26 & 1.08 & 0.82 & \\
\hline & & & & 0.73 & 1.14 & 0.54 & \\
\hline & & & & 0.71 & 1.16 & 0.54 & \\
\hline PAR & OR C & NOS & & & 0.66 & & \\
\hline & BARS & & & & 0.67 & & \\
\hline
\end{tabular}




\section{FIGURE 3. AVERAGE AXIAL POWER DISTRIBUTION, TIME $=0$}

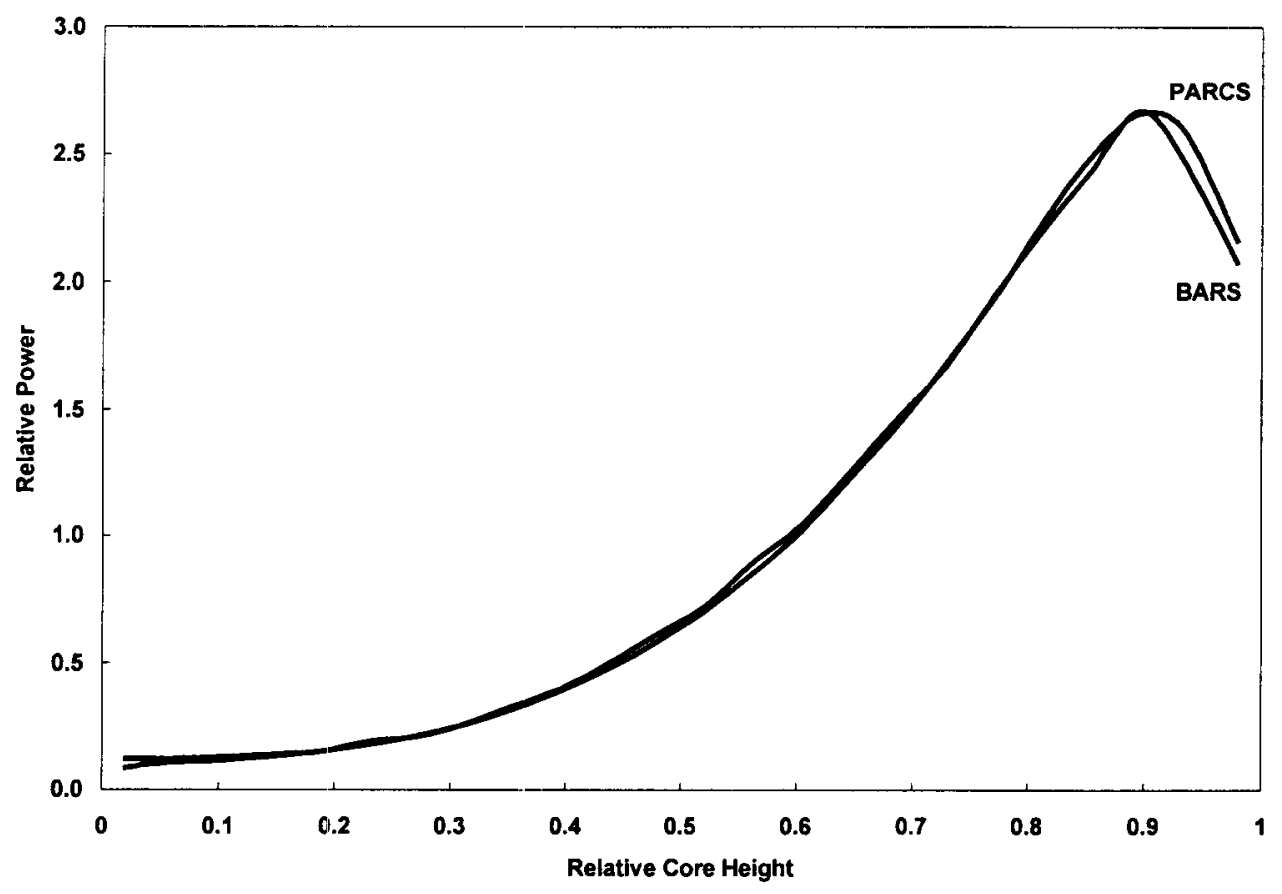

\section{Results for the REA}

The REA was defined for the center control rod at hot zero power conditions with an ejection time of $100 \mathrm{~ms}$. Since that rod has an actual worth of $347 \mathrm{pcm}$ and the delayed neutron fraction $(\beta)$ for the core is 0.005211 this would result in a power excursion below prompt-critical. Since the only power excursions that might lead to fuel damage are above prompt critical, the control rod worth was adjusted to obtain a worth of $1.2 \beta(\$ 1.2)$. In this way the intercomparison would test the codes for a case simulating the limiting situation. The fixed rod worth further assured that the results of the intercomparison would be dependent on the solution of the neutron kinetics equations during the event rather than on the initial conditions. The disadvantage of this approach was that each code did the modification to achieve the same rod worth differently. PARCS used a multiplier on the absorption cross section of the central assembly, BARS multiplied diagonal elements of the lambda matrix for the control rod, and CRONOS2 normalized the source term (fission rate) across the core.

The results for the total core power are given in Figure 4 for PARCS, CRONOS2, and BARS and the results for reactivity components from PARCS are given in Figure 5 along with the total reactivity from CRONOS. The behavior is typical for an REA; a power spike turned around by Doppler feedback, followed by a period of low power decaying away. In this calculation the reactor trip is delayed to simplify the intercomparison. Normally the shutdown banks would enter the core and their effect would be felt starting at around two seconds. As seen in Figure 5, the moderator feedback is as strong as the Doppler feedback but it enters delayed and, therefore, has a much smaller effect. 
FIGURE 4. CORE POWER DURING REA

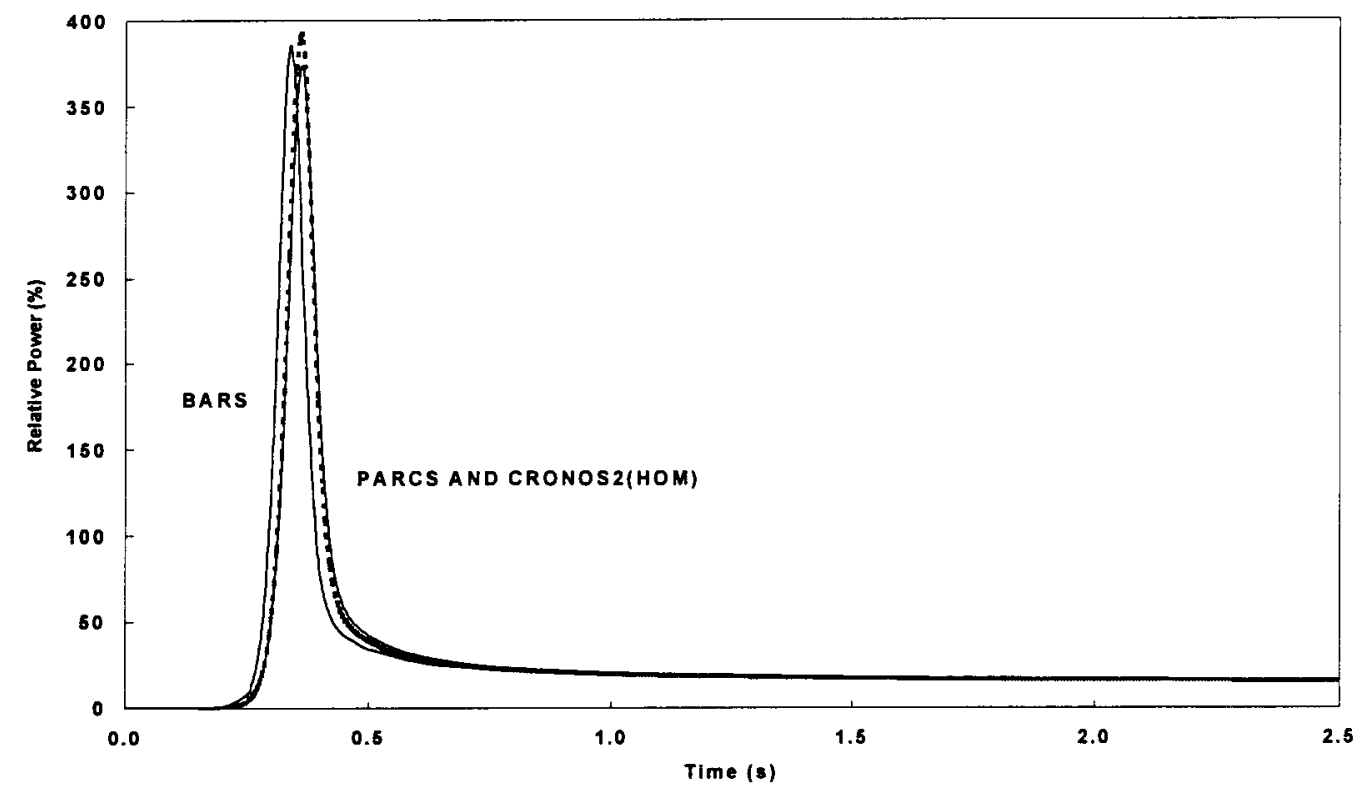

FIGURE 5. REACTIVITY COMPONENTS DURING REA

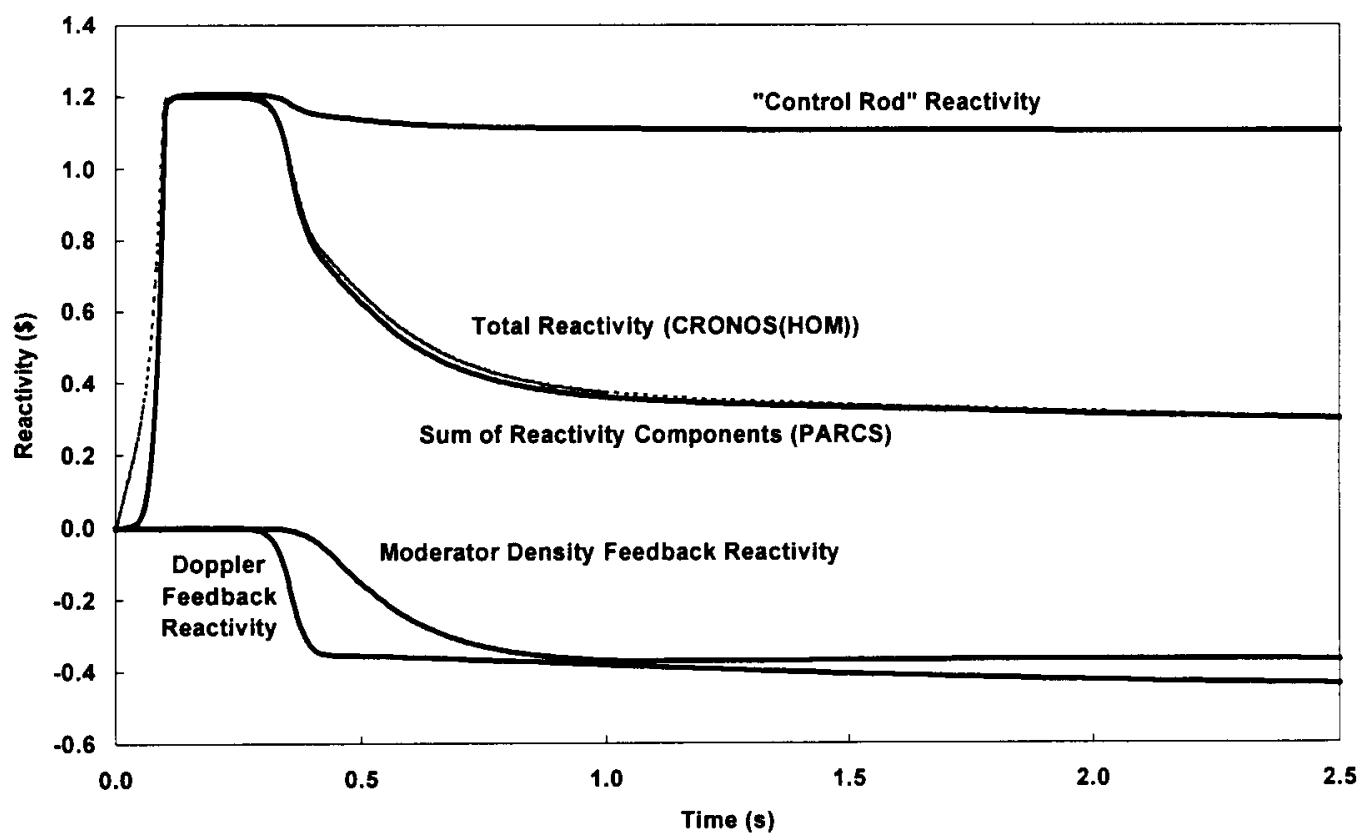


The details of the power pulse, namely, the peak power, time of the peak, and the pulse width are given for all three codes in Table 3 . The agreement is very good between BARS and the two codes using the homogeneous assembly representation. Also given in Table 3 is the maximum assembly fuel enthalpy in cal $/ \mathrm{g}$. In all calculations this is found in axial node 22 (out of 24) at the top of the core and in Assembly $9 \mathrm{H}$ which is the assembly adjacent to the center assembly (see Figure 1). Note that having the peak at the top of the core is . consistent with the axial power distribution shown in Figure 3. The axial power distribution is not significantly different after ejection of the central rod.

\begin{tabular}{|l|c|c|c|}
\hline \multicolumn{4}{|c|}{ TABLE 3. TRANSIENT PARAMETERS } \\
\hline \hline & PARCS/R5 & BARS/R5 & SAPHYR \\
\hline Control Rod Worth, \$ or “ $\beta$ ” & 1.206 & 1.209 & 1.196 \\
\hline Peak Power, \% Nominal & 393 & 386 & 374 \\
\hline Time of Peak, ms & 360 & 338 & 360 \\
\hline Pulse Width, ms & 65 & 63 & 69 \\
\hline $\begin{array}{l}\text { Maximum Assembly Fuel } \\
\text { Enthalpy, cal/g }\end{array}$ & 32.9 & 34.9 & N/A \\
\hline
\end{tabular}

The assembly fuel enthalpy as a function of time for Assembly 9H is given in Figure 6 for both PARCS and BARS. The difference at time zero is artificial as both calculations correspond to the same initial temperature $\left(278^{\circ} \mathrm{C}\right)$ but each code defined zero enthalpy at a slightly different temperature. The peak occurs at the end of the transient calculation ( $2.5 \mathrm{~s}$ in this case) since reactor trip has not yet been felt and the power generation is still high enough to continue to increase fuel temperature. Assuming that both calculations use the same zero point for enthalpy, the difference between the two results is approximately $2 \mathrm{cal} / \mathrm{g}$ while the increase in fuel enthalpy is approximately $18 \mathrm{cal} / \mathrm{g}$.

The difference in assembly enthalpy at other locations is expected to be proportionally less as the increase in enthalpy at other locations is less. One indication of this is that the average assembly power distribution is tracked similarly by all three codes. Figure 7 shows the radial power at the time of the peak of the power pulse and, with the exception of the center assembly, the agreement between the results is excellent. As mentioned above, it was the center assembly that was treated differently by each code in order to obtain equal rod worths.

In this transient it is of interest to note that although the peak power (enthalpy) is located in the four assemblies adjacent to the center assembly where the rod was ejected, the power is almost as high in the 20 assemblies surrounding those assemblies. These correspond to the assemblies with burnups of 58,56 , and $31 \mathrm{GWd} / \mathrm{t}$ near the central region as shown in the one-eighth core in Figure 1. 


\section{FIGURE 6. ASSEMBLY FUEL ENTHALPY AT LOCATION OF MAXIMUM}

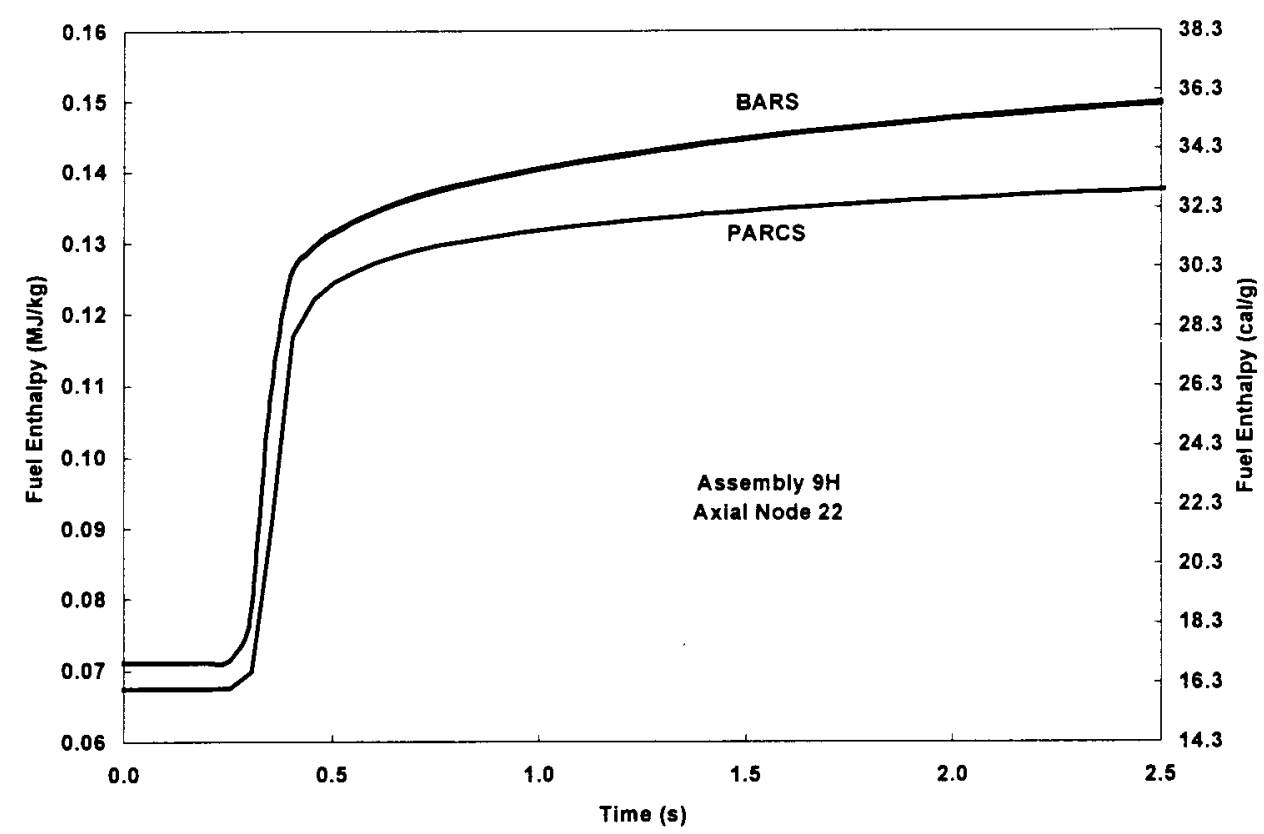

FIGURE 7. AVERAGE RADIAL POWER AT TIME $=\mathrm{t}-\mathrm{max}$

\begin{tabular}{|c|c|c|c|c|c|c|c|}
\hline 1.69 & 2.62 & 1.87 & 1.73 & 0.67 & 0.79 & 0.35 & 0.25 \\
\hline 2.06 & 2.62 & 1.87 & 1.72 & 0.66 & 0.78 & 0.34 & 0.25 \\
\hline \multirow[t]{13}{*}{2.07} & 2.64 & 1.86 & 1.71 & 0.65 & 0.76 & 0.34 & 0.24 \\
\hline & 1.97 & 2.00 & 1.36 & 1.23 & 0.57 & 0.82 & 0.34 \\
\hline & 1.97 & 2.00 & 1.36 & 1.22 & 0.56 & 0.82 & 0.37 \\
\hline & 1.95 & 1.98 & 1.34 & 1.22 & 0.56 & 0.83 & 0.33 \\
\hline & & 0.90 & 1.34 & 1.04 & 1.18 & 0.97 & 0.35 \\
\hline & & 0.89 & 1.33 & 1.04 & 1.18 & 0.98 & 0.35 \\
\hline & & 0.87 & 1.32 & 1.09 & 1.21 & 1.00 & 0.35 \\
\hline & & & 0.65 & 1.13 & 0.93 & 0.69 & \\
\hline & & & 0.64 & 1.13 & 0.93 & 0.69 & \\
\hline & & & 0.63 & 1.13 & 0.94 & 0.70 & \\
\hline & & & & 0.64 & 1.00 & 0.46 & \\
\hline & & & & 0.64 & 1.00 & 0.46 & \\
\hline & & & & 0.62 & 0.99 & 0.46 & \\
\hline PARCS & $360 \mathrm{~ms}$ & & & & 0.57 & & \\
\hline CRONOS & $360 \mathrm{~ms}$ & & & & 0.57 & & \\
\hline BARS & $340 \mathrm{~m} \mathrm{~s}$ & & & & 0.56 & & \\
\hline
\end{tabular}

The parameter of most interest during the REA is the fuel enthalpy distribution (i.e., the pellet-average enthalpy for each pin at every axial mesh). Historically, this value has been obtained by taking the result for the assembly fuel enthalpy and superimposing a form function which accounts for the intra-assembly power 
distribution. The pin power distribution from a calculation of the isolated assembly, with reflecting boundary conditions, at nominal conditions, has sometimes been used. However, it is well-known that this is a poor way to synthesize the pin-by-pin power distribution during a transient and flux reconstruction methods exist in order to obtain results when the neutron kinetics is done with an homogenized assembly representation (e.g., as in PARCS). The flux reconstruction method provides pin power which can be integrated to obtain an estimate of fuel enthalpy or, more simply, the assembly fuel enthalpy can have the pin-by-pin power superimposed as the form function to provide the local fuel enthalpy. In either approximation, the local fuel temperature/enthalpy is not being calculated explicitly.

An intercomparison of PARCS and BARS for the pin-by-pin power along with the (small) differences seen for the assembly power gives an idea of what the intercomparison would be for the pin-by-pin fuel enthalpy. The pin power distribution within the assembly with the peak value of enthalpy is given at time zero in Figures 8 and 9 for the two codes. Figure 8 shows the distribution throughout the assembly with the orientation of the $\mathrm{x}$-axis of the reactor noted (see also Figure 1) whereas Figure 9 shows the results for a trace across the assembly at the position of the $\mathrm{x}$-axis. In both figures the positions where the pin power is zero correspond to the presence of either a control rod guide tube or instrumentation thimble instead of fuel.

FIGURE 8. PIN POWER FOR ASSEMBLY 9H AT TIME $=0$

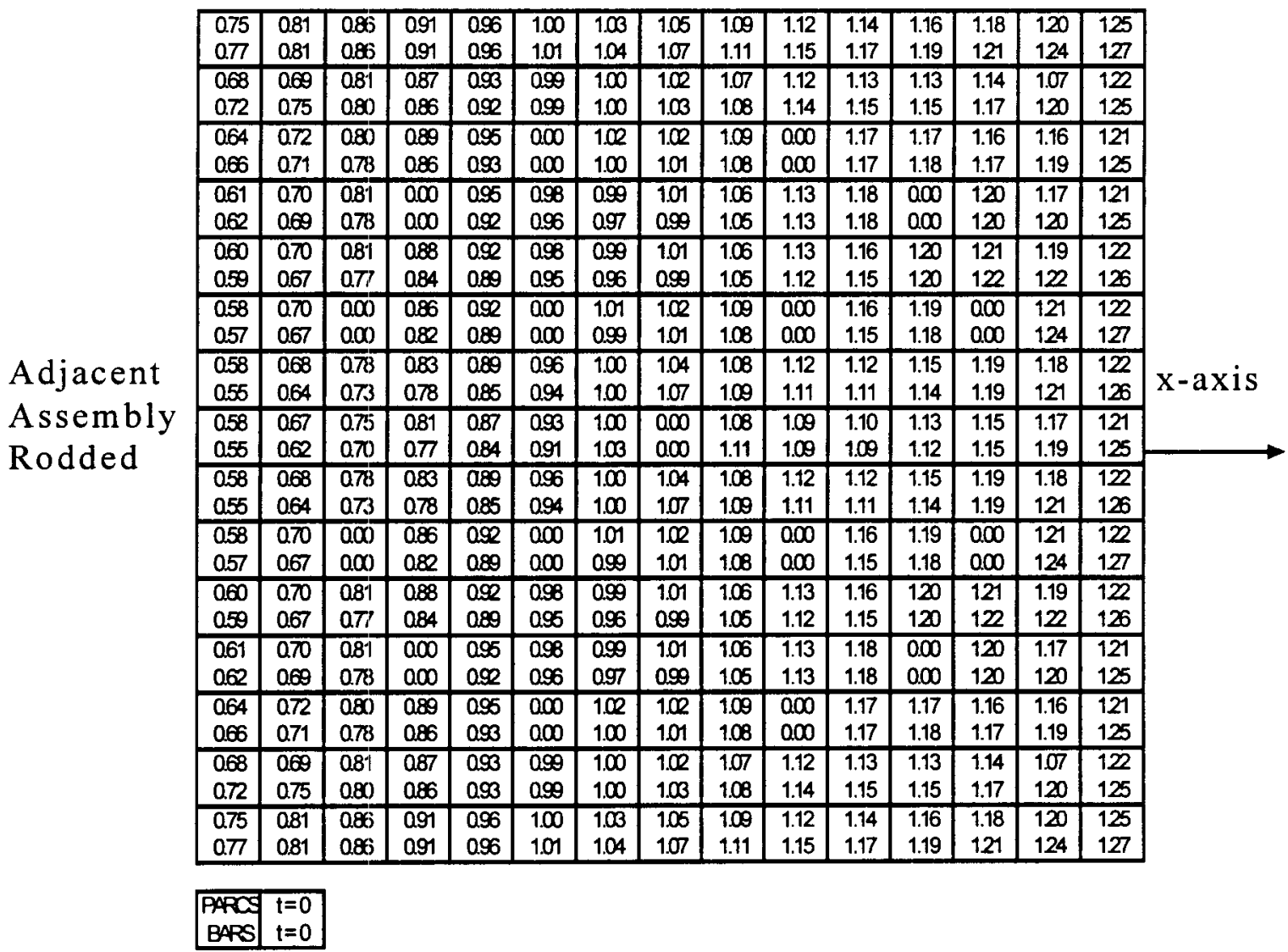




\section{FIGURE 9. RELATIVE PIN POWER ACROSS ASSEMBLY 9H TIME $=0$}

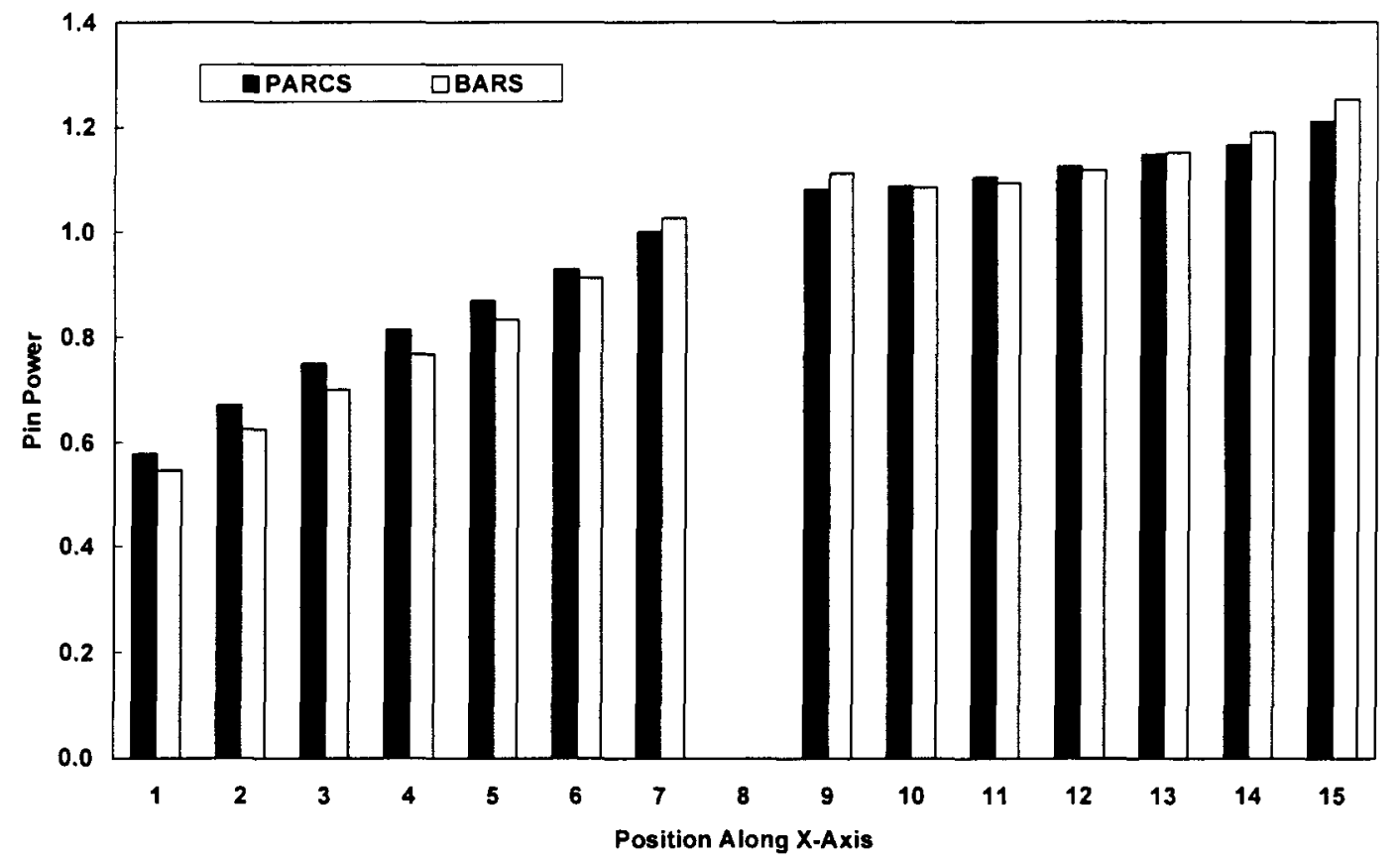

For the comparison shown, the full capability of the PARCS reconstruction method was not used. Corner point discontinuity factors can be used in the reconstruction but were not available from the isolated assembly calculation and values of 1.0 were assumed. The two-group form functions were also not available and hence the pin-by-pin power distribution from the isolated assembly was used for those form functions. With these limitations the rms (root mean square) difference between the two results is $3.1 \%$ and the maximum difference (with one exception) is less than $5 \%$, indicating good agreement between the totally different methods for treating the intra-assembly neutron kinetics. Note that this agreement is for an assembly with a steep gradient along the $\mathrm{x}$-axis. As can be seen in Figure 9, the pin power increases by a factor of two across the assembly [as a result of the presence of the control rod in the (core center) assembly adjacent to the assembly being analyzed]. The exception to the good agreement is an error of $\sim 10 \%$ in pins containing gadolinium. This is probably the result of differences in the treatment of the depletion of $\mathrm{Gd}$ in the codes providing data to PARCS and BARS.

A similar comparison of pin power distributions is given in Figures 10 and 11 at the time at which the total power is a maximum. In this case the power distribution across the assembly is relatively flat--all adjacent assemblies are uncontrolled--and the rms difference between the two sets of data is reduced to $1.7 \%$ and the maximum difference to less than $2 \%$ except in the gadolinium-containing pins. 
FIGURE 10. PIN POWER FOR ASSEMBLY 9H AT TIME = t-max

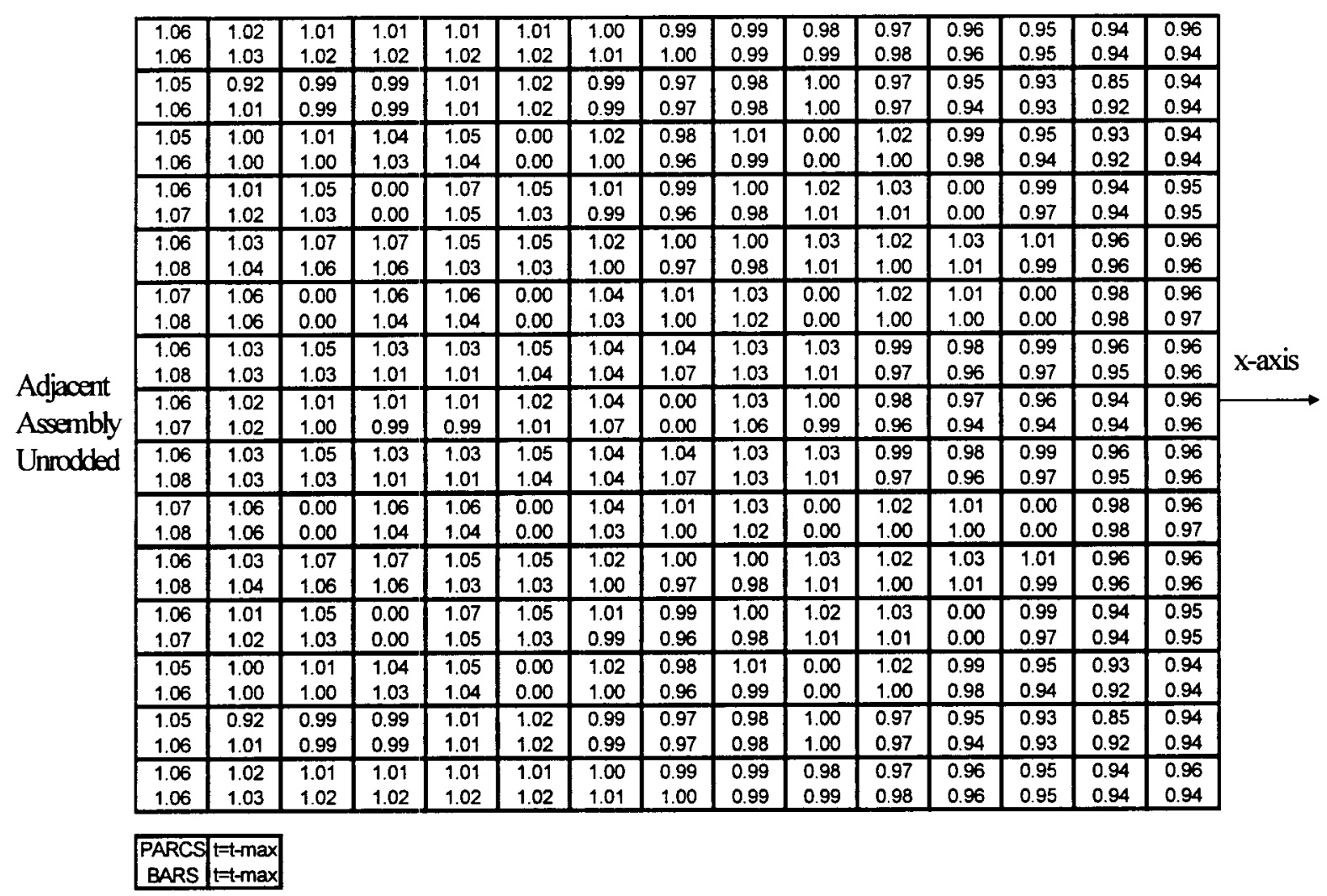

FIGURE 11. RELATIVE PIN POWER ACROSS ASSEMBLY 9H TIME = t-max

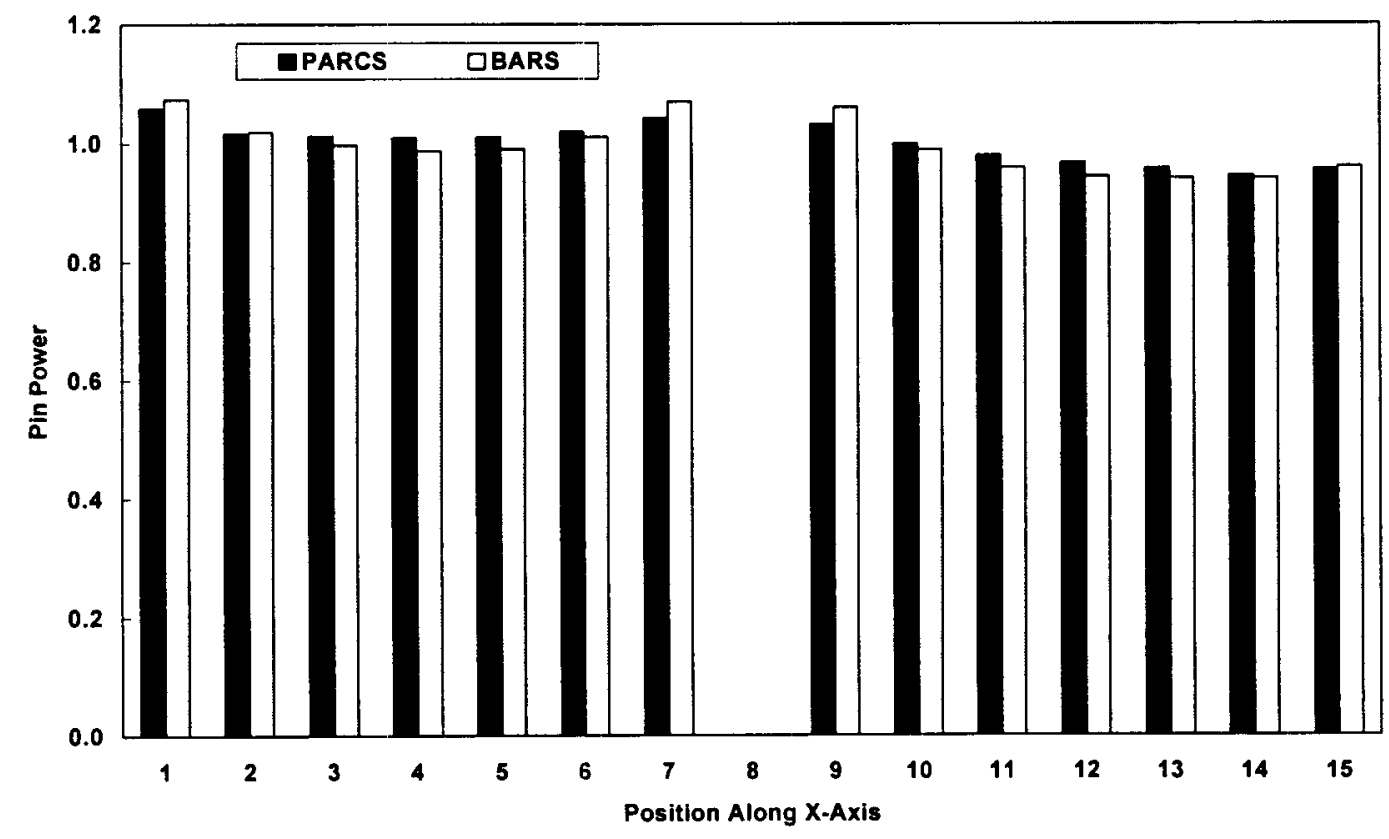




\section{Summary}

An intercomparison of results for an REA has been carried out using three different code systems used in the U.S., the R.F., and France. The neutron kinetics in these systems is based on the PARCS, BARS, and CRONOS2 codes, respectively. The results give an indication of the uncertainty in the calculated local fuel enthalpy. In particular, since two very different methods of solving the space-dependence of the flux across an assembly, the intercomparison gives an indication of the uncertainty that arises due to the spatial representation within the fuel assembly. PARCS and CRONOS use an homogenized assembly representation whereas BARS uses a heterogeneous representation of each fuel pin. In the future an additional comparison will be made with a version of CRONOS that models each fuel cell explicitly.

In order to limit the differences between codes to the intra-assembly representation to the extent possible, an attempt was made to make the models equivalent in all other ways. The most difficult aspect of this was the treatment of the core-reflector interface. The success of the equivalence was judged by the good agreement obtained for steady state power distribution and control rod and thermal-hydraulic feedback reactivity. All quantities were within limits established by the participants prior to the start of calculations.

Several quantities were compared during the transient. Total power, including the peak power, time of the peak, and pulse width were in excellent agreement using all three methods. The calculated assembly average fuel enthalpy at the axial location at which it was greatest during the REA increased by approximately 18 $\mathrm{cal} / \mathrm{g}$ from an initial value of $14 \mathrm{cal} / \mathrm{g}$. The difference between the peak assembly fuel enthalpy using an homogenized assembly (PARCS and CRONOS) and using a heterogeneous model which represented each fuel pin explicitly (BARS), was $2 \mathrm{cal} / \mathrm{g}$. The differences are expected to increase with an increase in the spatial gradient of power. The expected variation can be tested with the data generated to date by looking at the results for different assemblies at different axial locations. The results also demonstrated that a large region of the core can be affected by an REA.

The calculated pin power was also compared using the flux reconstruction model in PARCS and the BARS heterogeneous model. The results showed excellent agreement except for fuel pins containing gadolinium with the rms difference at time zero being only $3.1 \%$ and at the time of the peak power the rms difference was $1.7 \%$. The difference between the two models was expected to increase with increasing gradient and these results are consistent with that expectation. The power across the assembly varied by more than a factor of two at time zero whereas at the time of the peak power the variation was only $\pm 8 \%$.

In the future it is expected that additional intercomparisons will be available with the heterogeneous version of CRONOS2 and that additional assemblies will be considered so that the uncertainty due to the spatial representation can be assessed more definitively. That work in conjunction with other efforts to understand the uncertainty as a result of variations in Doppler feedback, control rod worth, delayed neutron fraction, etc. should lead to a better estimate of the uncertainty in calculated fuel enthalpy using best-estimate methods. 


\section{$\underline{\text { References }}$}

1. R.O. Meyer et al., "A Regulatory Assessment of Test Data for Reactivity-Initiated Accidents," Nuclear Safety, 37, No. 4, October-December 1996.

2. H. G. Joo et al., "PARCS: A Multi-Dimensional Two-Group Reactor Kinetics Code Based on the Nonlinear Analytic Nodal Method, PU/NE-98-26, Purdue University, September 1998.

3. A. Avvakumov and V. Malofeev, "Validation of an Advanced Heterogeneous Model for LWR Detailed Pin-by-Pin Calculations," Proceedings of the International Conference on the Physics of Nuclear Science and Technology, Long Island, NY, October 1998.

4. S. Loubière et al., “APOLLO2 Twelve Years Later,” NT SERMA/LENR/PU/99-2557/B

5. J. J. Lautard, S. Loubière, C. Fedon-Magnaud, "CRONOS2, A Modular Computational System for Neutronic Core Calculations," IAEA Specialist Meeting on Advanced Calculational Methods for Power Reactors, Cadarache, France.

6. I. Toumi, D. Gallo, A. Bergeron, and E. Royer, "Advanced Numerical Methods for ThreeDimensional Two-Phase Flow Calculations in PWR," NURETH-8 Conference, Kyoto, Japan.

7. K.N. Ivanov et al., "Pressurized Water Reactor Main Steam Line Break (MSLB) Benchmark; Volume I: Final Specifications,"NEA/NSC/DOC(99)8, U.S. Nuclear Regulatory Commission and OECD Nuclear Energy Agency, April 1999. 